\title{
AUREOMYCIN THERAPY IN LARYNGOSCLEROMA
}

\author{
A REPORT ON FIVE CASES \\ By A. EL-HAKEEM, FZZ. EL-SAMMA, and I. MOSSALLAM \\ (From the Abbassia Faculty of Medicine, Cairo)
}

SCleroma is a granuloma which affects the upper air passages and is fairly common in Egypt.

The disease process runs a chronic course, and according to some observers subsides spontaneously after twenty or more years, ending in fibrosis which may cause deformity, atresia, or complete obstruction.

Laryngoscleroma has a special interest because laryngeal atresia may take place in any stage of this disease. In the atrophic stage by the scabs which form, in the nodular stage by the masses themselves, in the cicatricial stage by the ultimate contraction of the scar.

Laryngoscleroma usually involves the subglottic region and upper end of the trachea, though the vocal cords are sometimes affected and the arytenoid region may share in the inflammation.

Five cases of laryngoscleroma are recorded because of the dramatic effect of aureomycin noticed in their treatment, while we were trying the effect of the various antibiotics on different cases of rhino- and laryngoscleroma in our Department.

CASE I. Male. Y. AY., age 23, was admitted to hospital on May 25th, I953, complaining of severe dyspnœa that required immediate tracheostomy. His breathing was not normal for the last six months prior to admission.

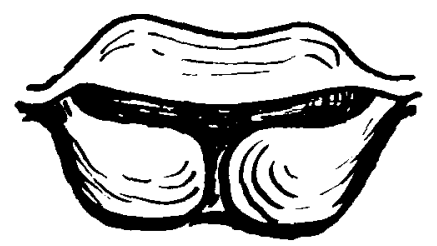

FIG. I.

Appearance of larynx in Case I.

Examination. Nose, pharynx and ears free.

Larynx revealed congestion of both arytenoids hiding the laryngeal inlet (Fig. I). No palpable glands in the neck. No history suggestive of syphilis or T.B. The Wassermann reaction was negative.

Radiological examination revealed irregular stenosing mass affecting the larynx and upper end of trachea (Fig. 2). 


\section{A. El-Hakeem, Ezz. El-Samma and I. Mossallam}

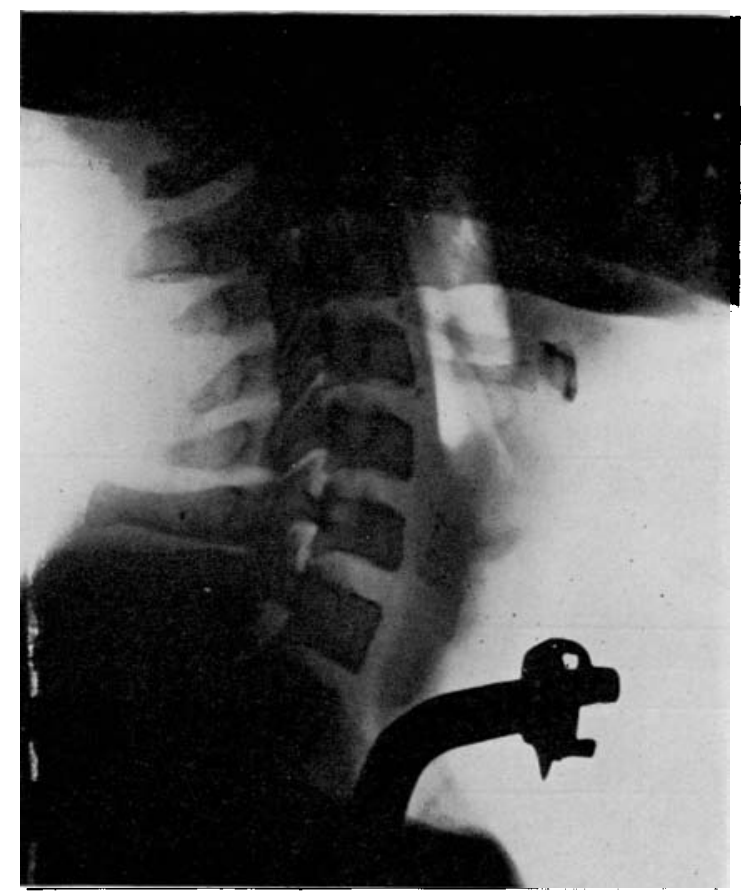

FIG. 2.

X-ray of larynx and trachea in Case I before treatment.

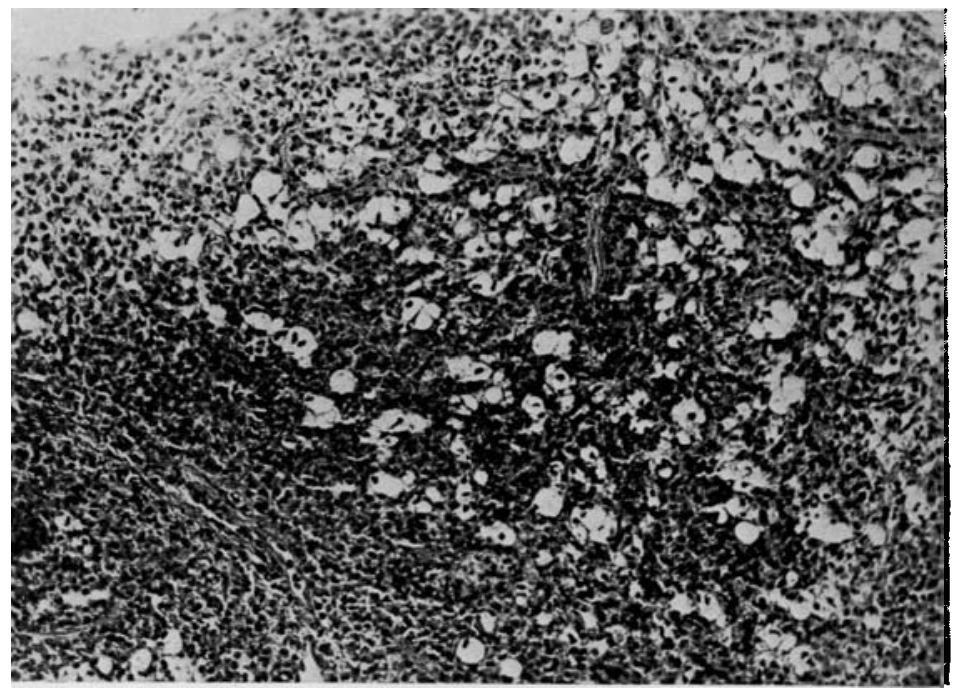

FIG. 3.

Photomicrography of biopsy from Case I, showing typical rhinoscleroma. 


\section{Aureomycin Therapy in Laryngoscleroma}

(Fig. 3)

Treatment. This patient was given penicillin and sulfa repeatedly with very little improvement.

On June $25^{\text {th, }}$ I953, chloromycetin therapy was started on the assumption that it has a wide spectrum of activity and will affect both the causal and overlying secondary infection, in doses of two capsules six hourly. After one week, some improvement took place, congestion diminished, but there was some pale cedema of the arytenoids and the subglottic region. This drug was continued for 46 days with very slow progress.

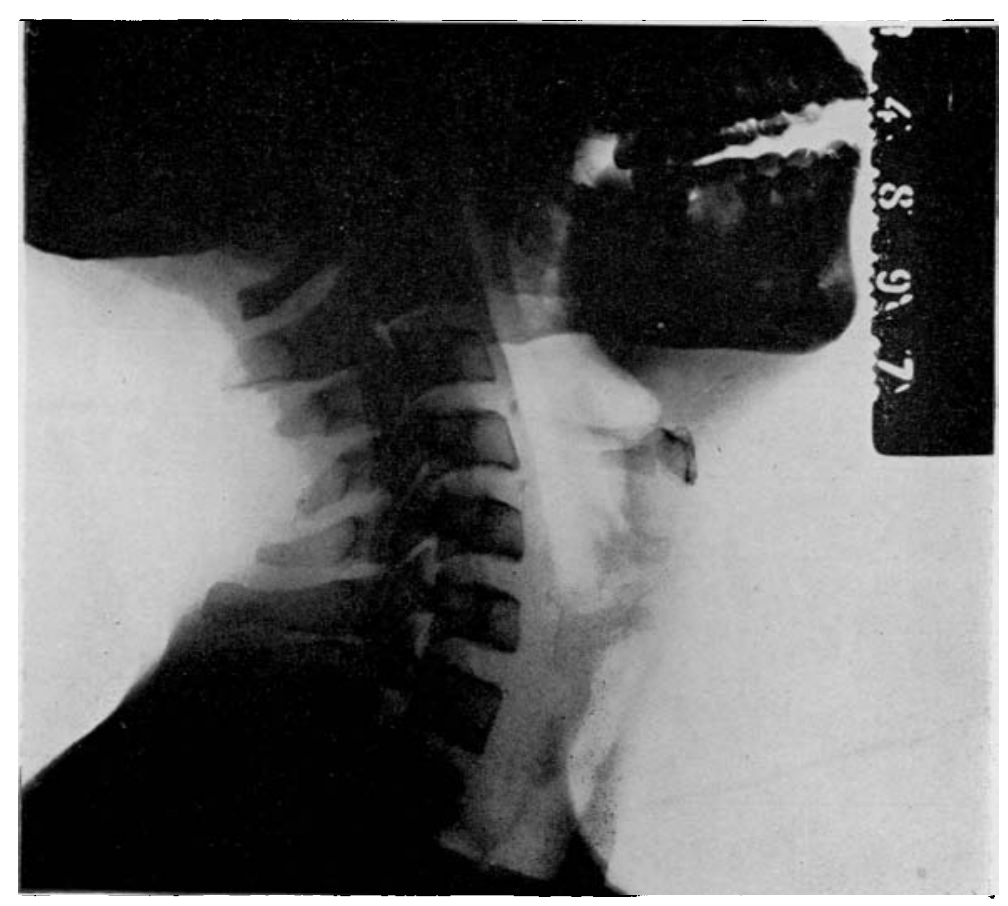

FIG. 4 .

$\mathrm{X}$-ray of Case I after treatment, showing a clear airway.

On August Irth, I953 we shifted to aureomycin, in doses of one capsule six-hourly. After two days only examination revealed much improvement; on the seventh day the subglottic area was almost clear, œdema of the arytenoids very much diminished. Six days later the larynx and subglottic area showed striking results, as the whole area was completely free, and the knee of the tracheostomy tube was clearly seen from above (Fig. 4).

After another five days while treatment was still being carried on the tube was plugged for two days with no evident distress, then it was dispensed with.

The patient was discharged as cured, he reports regularly in the out-patient department with no complaint and clinically free.

In this case aureomycin therapy was used for 20 days. 


\section{A. El-Hakeem, Ezz. El-Samma and I. Mossallam}

CASE II. Female, age I6. A.A.F. Complaining of attacks of laryngeal obstruction, hoarseness of voice, cough, and occasional expectoration of black scabs. No history suggestive of syphilis, mycosis, or T.B. The Wassermann reaction was negative.

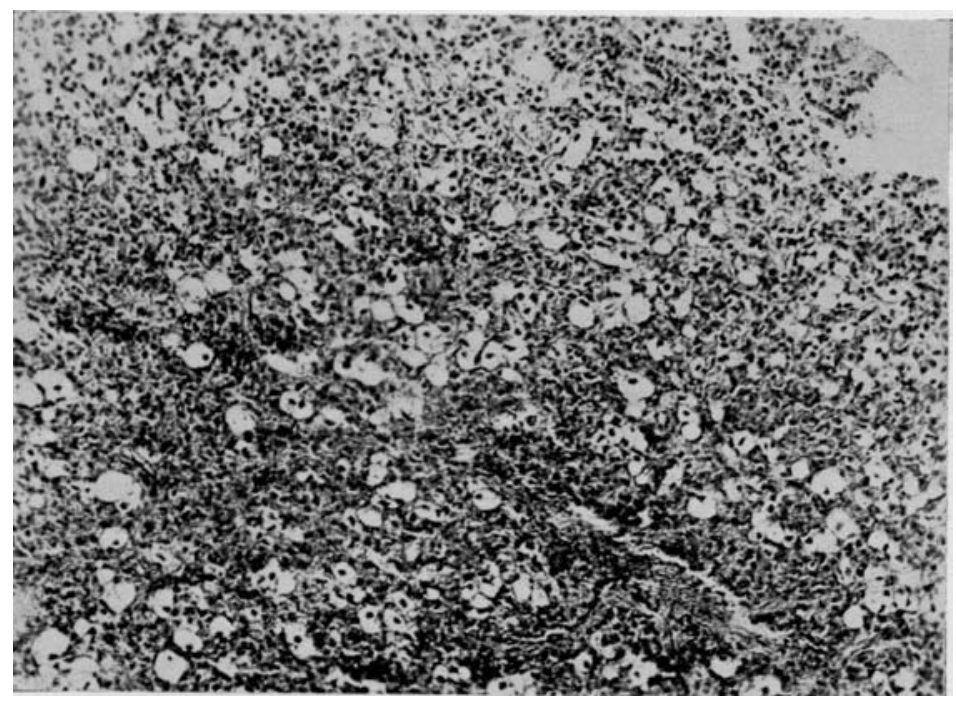

FIG. 5

Photomicrography of biopsy from Case II, showing rhinoscleroma.

Examination. Nose, dry scabs with no obstruction, after removal, the mucosa lining the anterior end of the right inferior turbinate looked slightly granular. Histopathological examination of this area proved to be typical rhino-scleroma (Fig. 5).

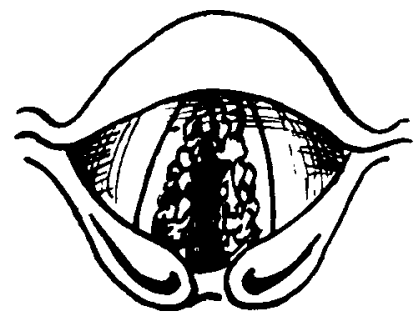

FIG. 6

Larvnx in Case II.

Nasopharynx and pharynx free.

Larynx revealed mild congestion of epiglottis, dry black scabs adherent to both vocal cords and interarytenoid region, the rima glottidis appearing as a narrow slit, the subglottic region could not therefore be seen well (Fig. 6).

There were no glands in the neck. 


\section{Aureomycin Therapy in Laryngoscleroma}

First radiogram (Fig. 7) showed partial obliteration of ventricular oval shadow and stenosis of upper end of trachea.

Treatment. Alkaline wash for the nose with instillation of liquid paraffin in nose and larynx to soften scabs. After this a subglottic mass could be seen; it was of a whitish non-ulcerating nature. The scabs, however, re-formed rapidly.

Streptomycin was given intramuscularly in half gramme doses twice daily, for 44 days. During this period examination revealed that the scabby condition of the nose and larynx sometimes improved and often recurs, but the subglottic mass was stationary.

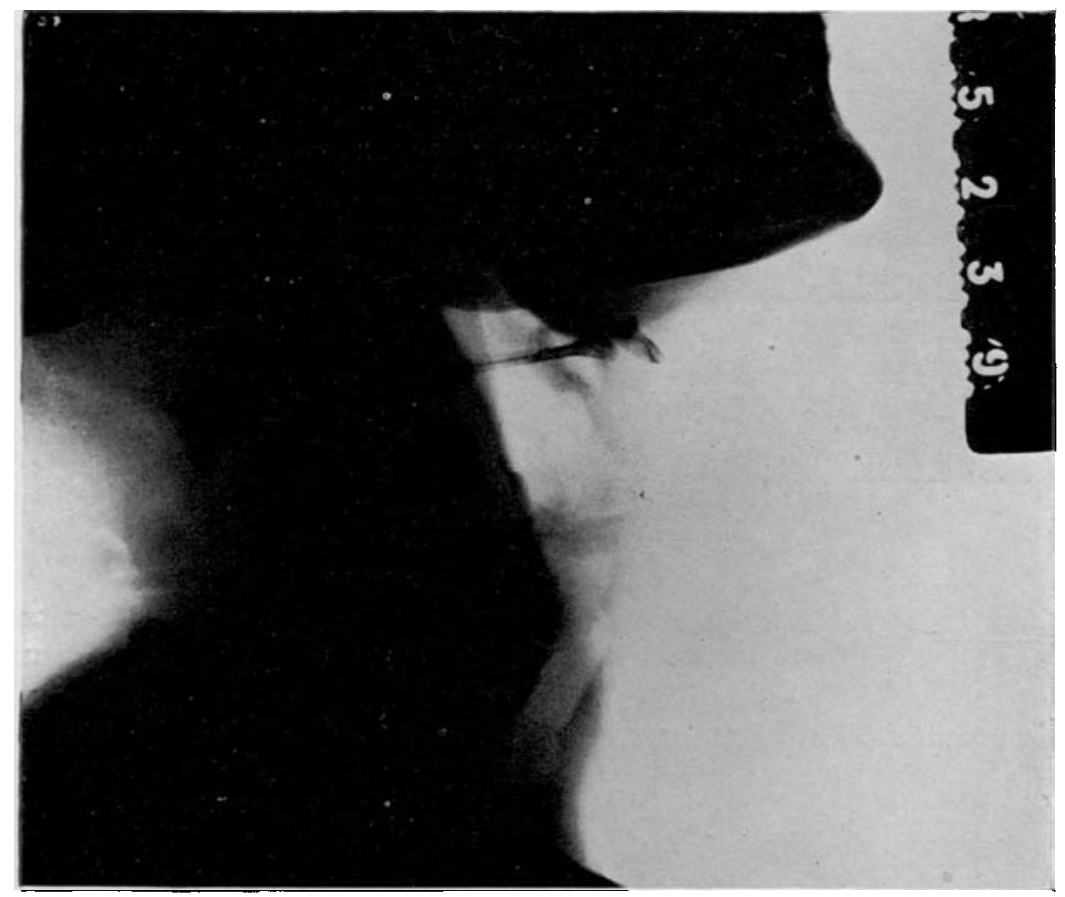

Fig. 7.

X-ray of larynx and trachea of Case II before treatment.

Now we thought of shifting to aureomycin therapy, in the form of one capsule every six hours. After Io days complete absence of scabs in both nose and larynx was noticed.

The subglottic mass was much smaller, and the edges of both vocal cords were slightly œedematous. After another ro days the subglottic mass completely disappeared.

Cough and dyspnœa were no more, and the patient was discharged as cured; she reports to the outpatient department free from symptoms (see Fig. 8). The oval shadow of the laryngeal ventricle is definitely clear and the lumen of the trachea much wider.

Aureomycin therapy in this case lasted also 20 days. 


\section{A. El-Hakeem, Ezz. El-Samma and I. Mossallam}

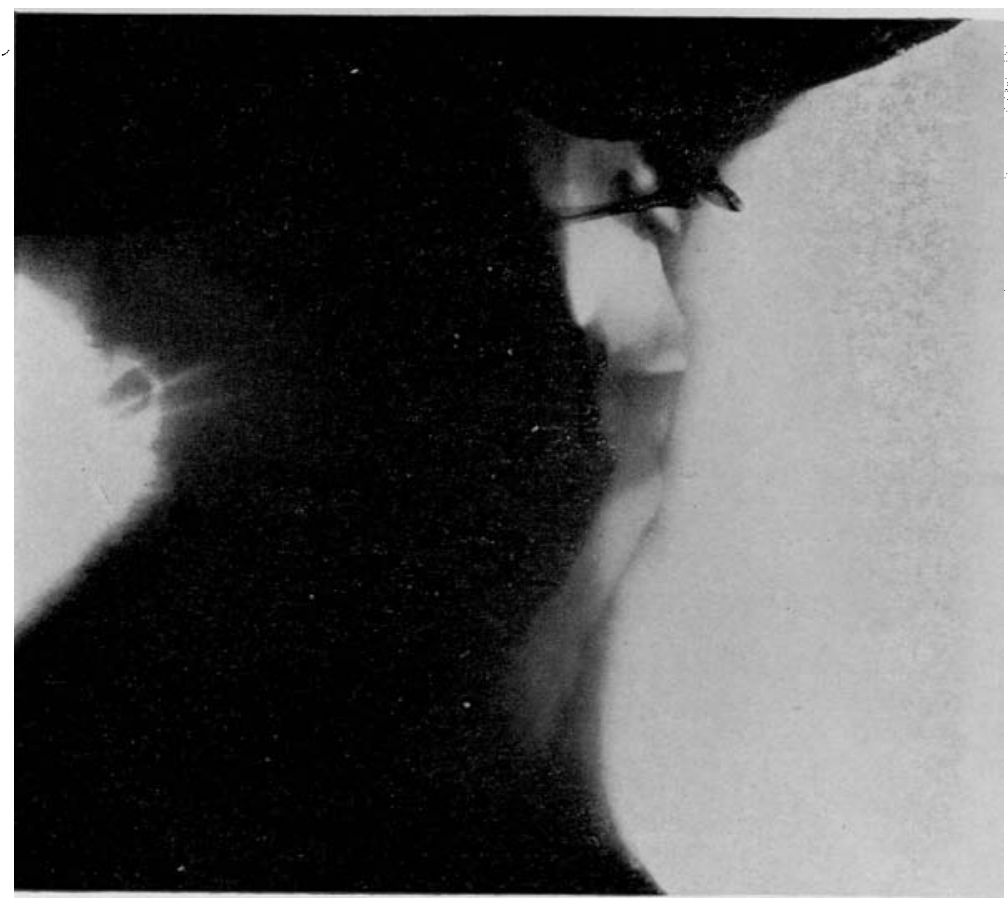

FIG. 8.

X-ray of Case II after treatment.

CASE III. Male, age 25. E.K. Complaining of hoarseness of voice and dyspnœa for two months, with occasional improvement, but never returning to normal.

Examination. The patient was very anæmic in appearance, the voice though hoarse yet of a soft nature. Nose and throat almost normal. Larynx showed cedema of both arytenoids with an irregular subglottic shadow that could be

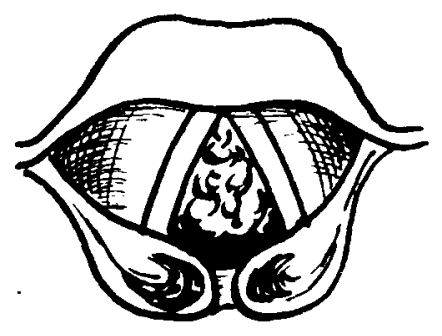

FIG. 9 .

Appearance of larynx in Case III.

seen with difficulty (Fig. 9). Repeated examination of chest, sputum and Wassermann were all negative, as the picture on admittance was suggestive of tubercular laryngitis. 


\section{Aureomycin Therapy in Laryngoscleroma}

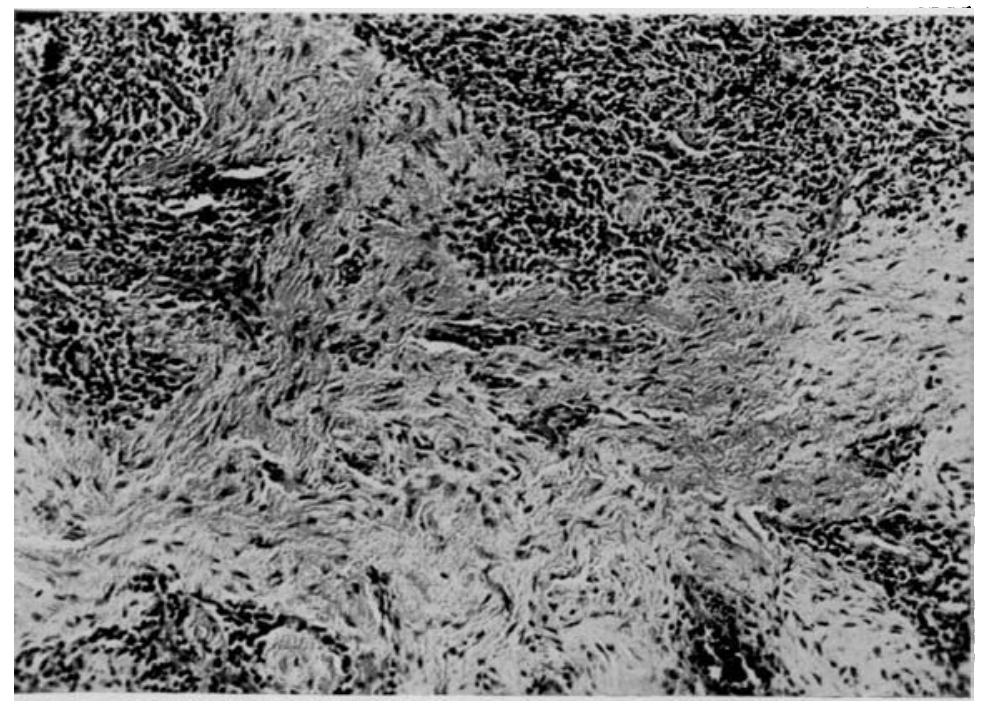

FIG. Io.

Photomicrography of biopsy from Case III.

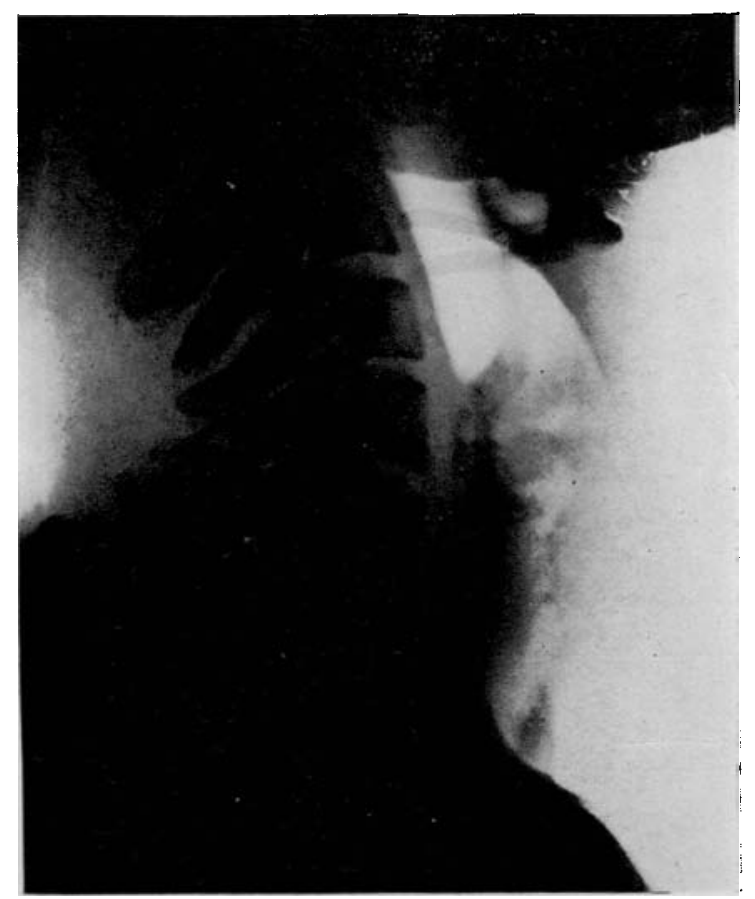

FIG. II

X-ray of Case III before treatment.

529 


\section{A. El-Hakeem, Ezz. El-Samma and I. Mossallam}

Direct examination of the larynx showed a whitish subglottic mass with irregular surface. By biopsy it proved to be scleroma (see Fig. Io).

Treatment. Streptomycin treatment was carried out for 3I days, with no improvement at all. Aureomycin was started in the usual dose, one capsule every six hours. After five days, the odema of the arytenoids started to subside, and now the subglottic mass could be easily seen by the laryngeal mirror. Five days later the subglottic area was absolutely free, and the œedema of the arytenoid region very much reduced. After another eight days, the subglottic area free, with the arytenoids normal, the patient was discharged as cured.

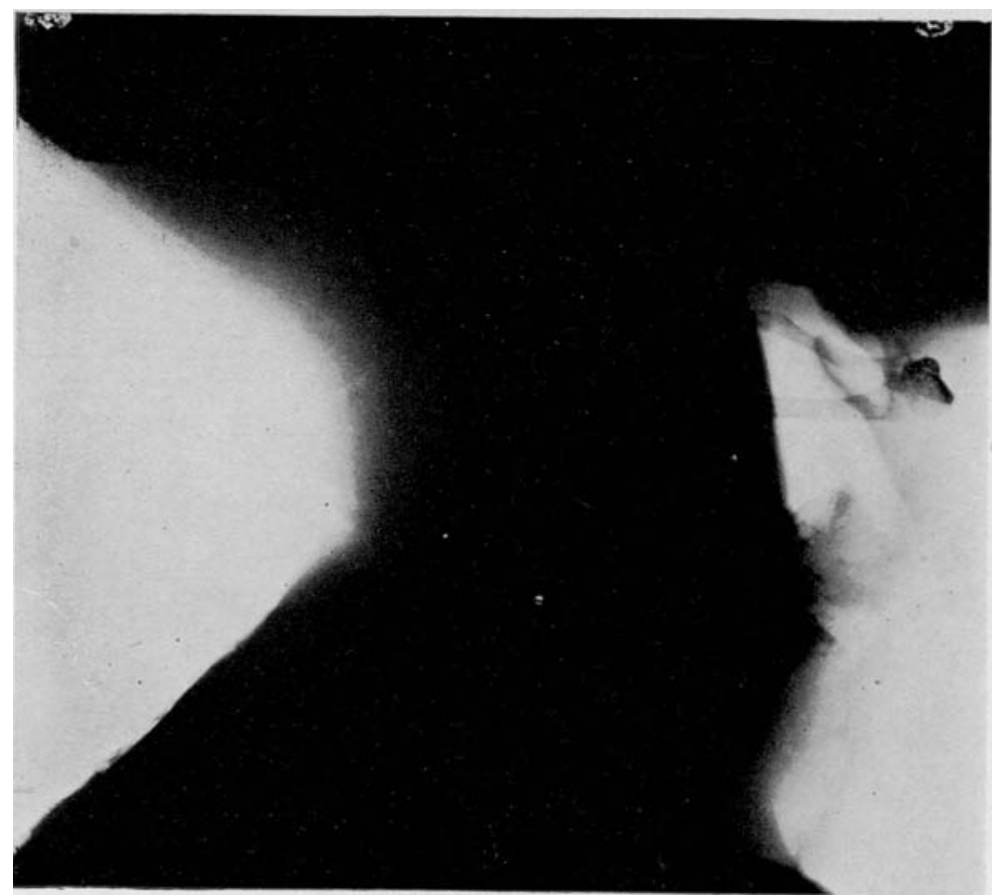

Fig. I 2.

X-ray of Case III after treatment.

A month later he reported with an absolutely clear and normal larynx.

Aureomycin was given for I 8 days. (See X-ray, before and after treatment, Figs. II and I2.)

CASE IV. Male, age 40. A.M.A. Complaining of total nasal obstruction accompanied by laryngeal obstruction causing severe dyspnœa, which necessitated tracheostomy on admission.

Examination. The nose was very swollen, the skin congested, and the nares were completely blocked by granulomatous masses, firm in consistency and slightly tender. He had epiphora, and the patient, in general, was in great distress.

Ears were free. The pharynx had scars with adhesions between the pillars and posterior pharyngeal wall. There was also scattered granulation tissue patches in active form.

Larynx. Both arytenoids are red and swollen with subglottic stenosis due 


\section{Aureomycin Therapy in Laryngoscleroma}

to scabs and granulation tissue. Biopsy from nose proved to be scleroma. (Fig. 13).

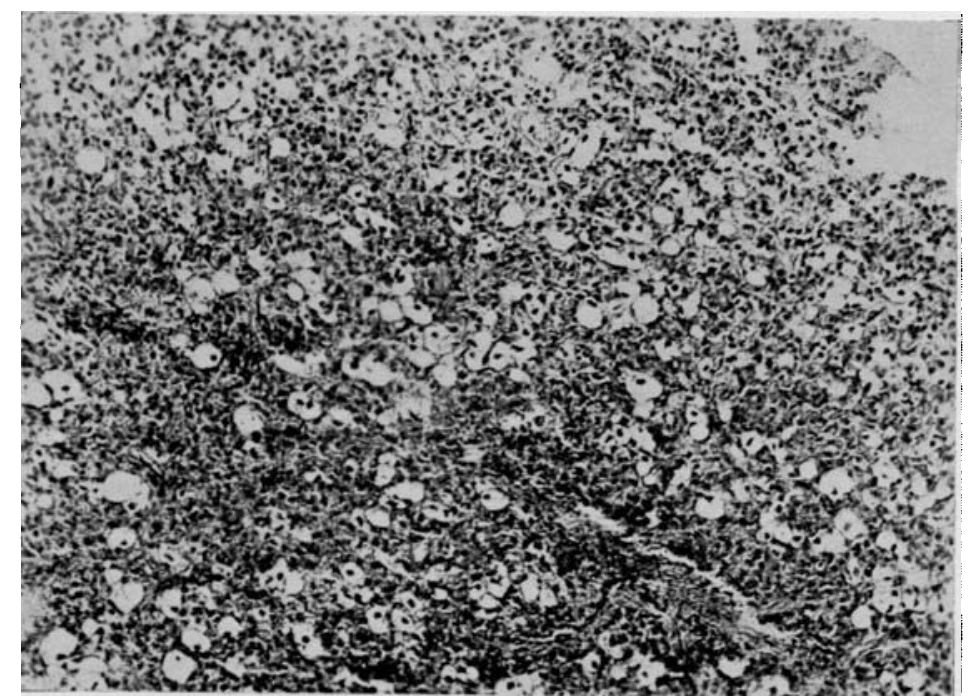

FIG. 13.

Photomicrography of biopsy from Case IV showing typical scleroma.

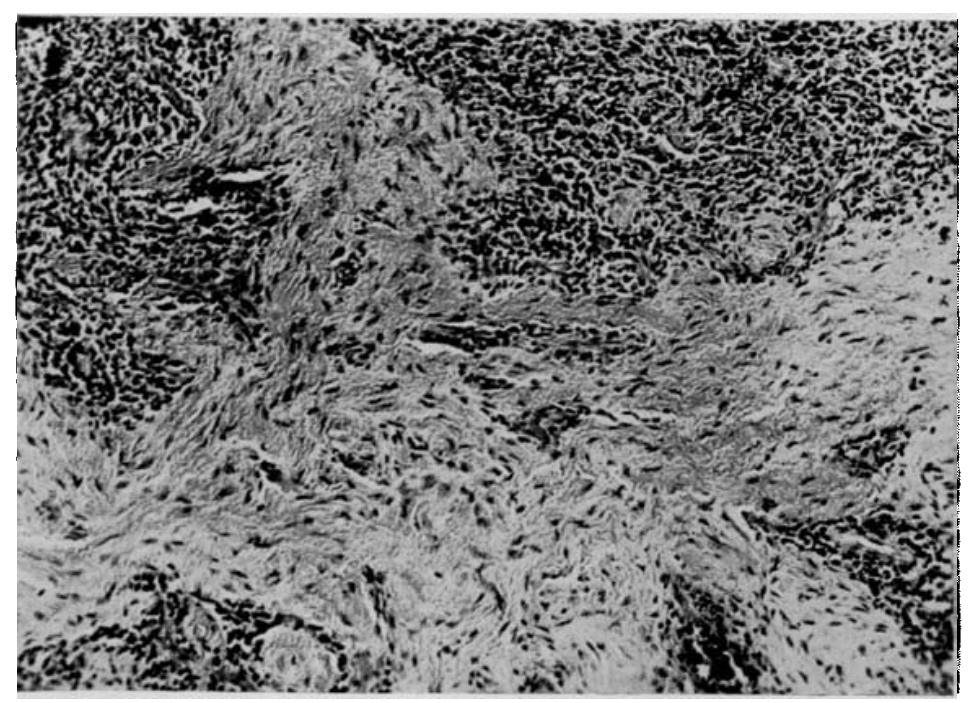

FIG, I4.

Showing evident fibrotic islands in Case IV

Treatment. Aureomycin therapy was started immediately after tracheostomy, one capsule in six-hourly doses for 37 days.

The result was most striking, as after seven days the nasal swelling started 


\section{A. El-Hakeem, Ezz. El-Samma and I. Mossallam}

to subside gradually, until on the thirtieth day the patient came to us glowing with happiness, saying that he started to breathe from his nose. On examining him we found that two minute apertures appeared through the diminishing mass inside his nose. After two days we plugged his tracheostomy tube, and found to our satisfaction that he could breathe freely. The tube, therefore, was discarded after two days.

A second biopsy was taken from the nose, the result was increasing fibrosis and insignificant specific cells (Fig. 14).

This case deserves some special comment, as with the long duration of aureomycin therapy there was no gastro-intestinal complaint, and no symptoms of the complications that might follow the long use of some of the new antibiotics.

Case V. Female, age 30. H.A. El-Fattah. Came to hospital with respiratory obstruction that required tracheostomy. The difficulty in respiration was

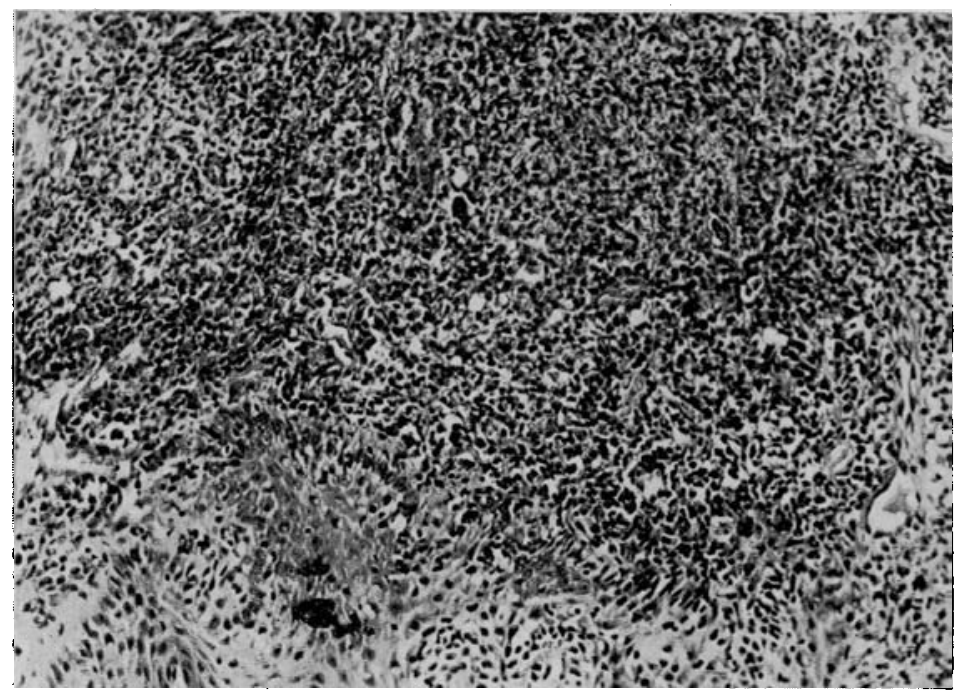

FIG. I 5

Photomicrography of biopsy from Case V showing scleroma.

present for the last six months accompanied with hoarseness of voice, which was gradually increasing; it became very distressing with attacks of suffocation in the last Io days.

On examination, nose, naso-pharynx and pharynx were free. Larynx showed a pale reddish mass occupying the anterior part of the subglottic region blocking more than half the rima glottidis. Both cords were normal in appearance and mobility.

Biopsy from the subglottic mass was reported to be scleroma (Fig. I5).

Treatment. Aureomycin therapy was given in the same doses as before for 33 days. The subglottic mass was found to be paler and ultimately formed a 


\section{Aureomycin Therapy in Laryngoscleroma}

fibrous constricting band causing laryngeal atresia with no evidence of activity. Biopsy (Fig. I6).

A laryngo-fissure was performed for this patient, the scar tissue excised and a Thiersch graft applied on a mould of vaseline gauze was fixed to the lumen of the larynx, after ten days the vaseline gauze was removed by direct laryngoscopy, and the graft was found to have taken nicely. The patient could dispense with the tube.

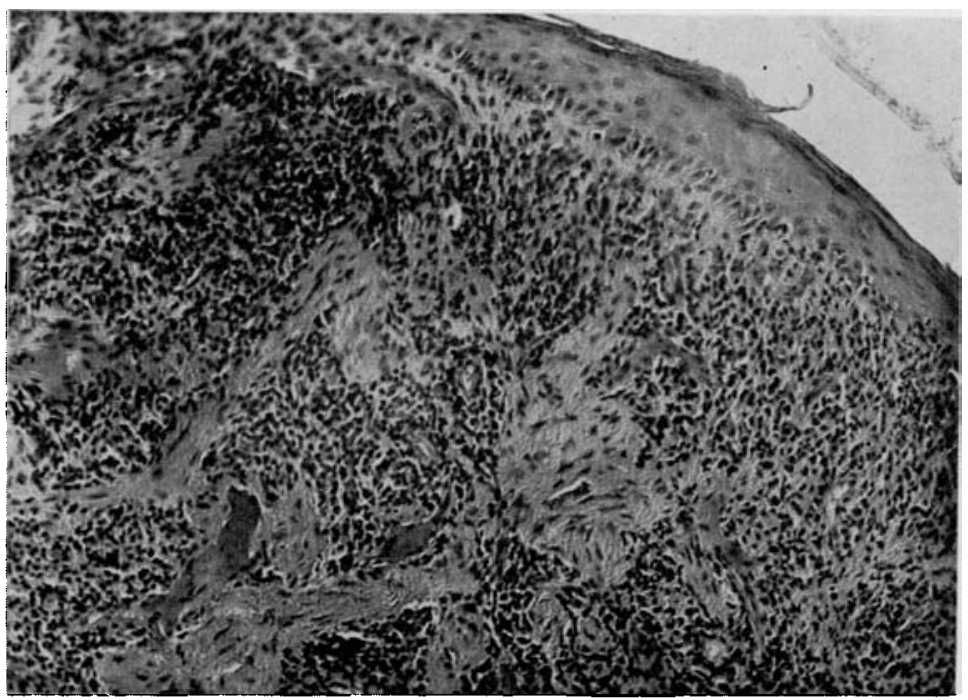

FIG. 16.

Case $\mathrm{V}$ after treatment showing advanced fibrosis with no evidence of activity.

\section{Comment}

The history of treatment in cases of rhino- and laryngoscleroma is rather interesting, as up till now, there was no definite line of successful therapy accepted universally.

Fittig suggested X-ray treatment since Igo3.

Von Eicken started radium therapy in 1905 .

Autogenous vaccine was said to be of benefit in the early stages, and in preventing spread of the disease.

Fever therapy was considered beneficial by some.

Surgical removal was also achieved by some surgeons, others were not in favour of surgery except for biopsy or tracheostomy.

Excision diathermy with suitable mechanical expanding pressure has been advocated. Treatment with mercury, N.A.B., local application of caustics, collosol iodine and Foadin, were said to give some results.

In our small series of cases we tried the effect of different antibiotics, aureomycin gave us the most striking curative results in a short time. 


\section{A. El-Hakeem, Ezz. El-Samma and I. Mossallam}

The average time for treatment of twenty days is sufficient for laryngoscleroma and early rhinoscleroma. In late cases longer therapy is needed. In cases I, III and V the scleroma was a primary lesion of the larynx. In cases II and IV it was both nasal and laryngeal. In all cases the upper end of the trachea was affected. 